\title{
NOTAS SOBRE O GÊNERO LIPPIA (VERBENACEAE) NO BRASIL
}

\author{
FÁTIMA REGINA G. SALIMENA* \& MARIA EMA MÚLGURA** \\ * Departamento de Botânica, Instituto de Ciências Biológicas, Universidade Federal de Juiz de Fora, \\ 36330-900 - Juiz de Fora, Minas Gerais, Brasil - e-mail: fatima.salimena@ufjf.edu.br \\ ** Instituto de Botánica Darwinion, Labardén 200, CC22, San Isidro, Buenos Aires, Argentina.
}

\begin{abstract}
Notes on the genus Lippia (Verbenaceae) in Brazil). New records of Lippia L. from Brazil are presented: L. tegulifera Briq. is a new record for Paraná and Rio Grande do Sul states and L. recolletae Morong for Distrito Federal, Goias and São Paulo states. Descriptions and illustrations to identify the taxa and geographic distribution are provided.
\end{abstract}

Key words: geographic distribution, new records, taxonomy

Resumo: (Notas sobre o gênero Lippia (Verbenaceae) no Brasil). Novos registros de Lippia L. do Brasil são apresentados: L. tegulifera Briq. é registrada nos estados do Paraná e Rio Grande do Sul e L. recolletae Morong para o Distrito Federal e os estados de Goiás e São Paulo. São apresentadas descrições e ilustrações para identificação dos táxons e sua distribuição geográfica é fornecida.

Palavras-chave: distribuição geográfica, novos registros, taxonomia

O gênero Lippia L. (Verbenaceae) reúne cerca de 150 espécies com maior riqueza na região neotropical (Atkins 2004) onde o Brasil se destaca como centro de diversidade com 98 espécies e alta porcentagem de endemismos, destacando-se os campos rupestres e cerrados (Salimena et al. 2013). $\mathrm{Na}$ flora do Brasil 18 espécies são citadas como ameaçadas ou raras (Salimena et al. 2009) e nove sob forte ameaça de extinção (Salimena et al. 2013). A Cadeia do Espinhaço é considerada o centro de diversidade do gênero reunindo mais da metade das espécies, havendo muitas em risco de extinção pela alteração dos ambientes naturais pela expansão agrícola e urbanização (Salimena et al. 2013).

O presente estudo faz parte do projeto de Repatriamento da Flora do Brasil (REFLORA/CNPq) e foi baseado na análise de literatura e de coleções depositadas nos herbários CEN, CESJ, HRCB, K, P e SI (acrônimos segundo Thiers 2014).

Lippia tegulifera Briq. é citada pela primeira vez para a flora brasileira, para os estados do Rio Grande do Sul e Paraná e Lippia recolletae Morong apresenta os primeiros registros para a flora dos estados de Goiás e São Paulo e Distrito Federal. São apresentadas descrições e ilustrações, para auxiliarem na identificação dos táxons, além da distribuição geográfica e comentários sobre a sua conservação.

Lippia recolletae Morong, Ann. New York Acad. Sc. 7: 196. 1892. Tipo: Paraguai. Central: Recoleta, cemetery 2 miles from Assunción, X-XI, 1888-1890, Morong 62 (holótipo NY!; isótipos G!, K!). 

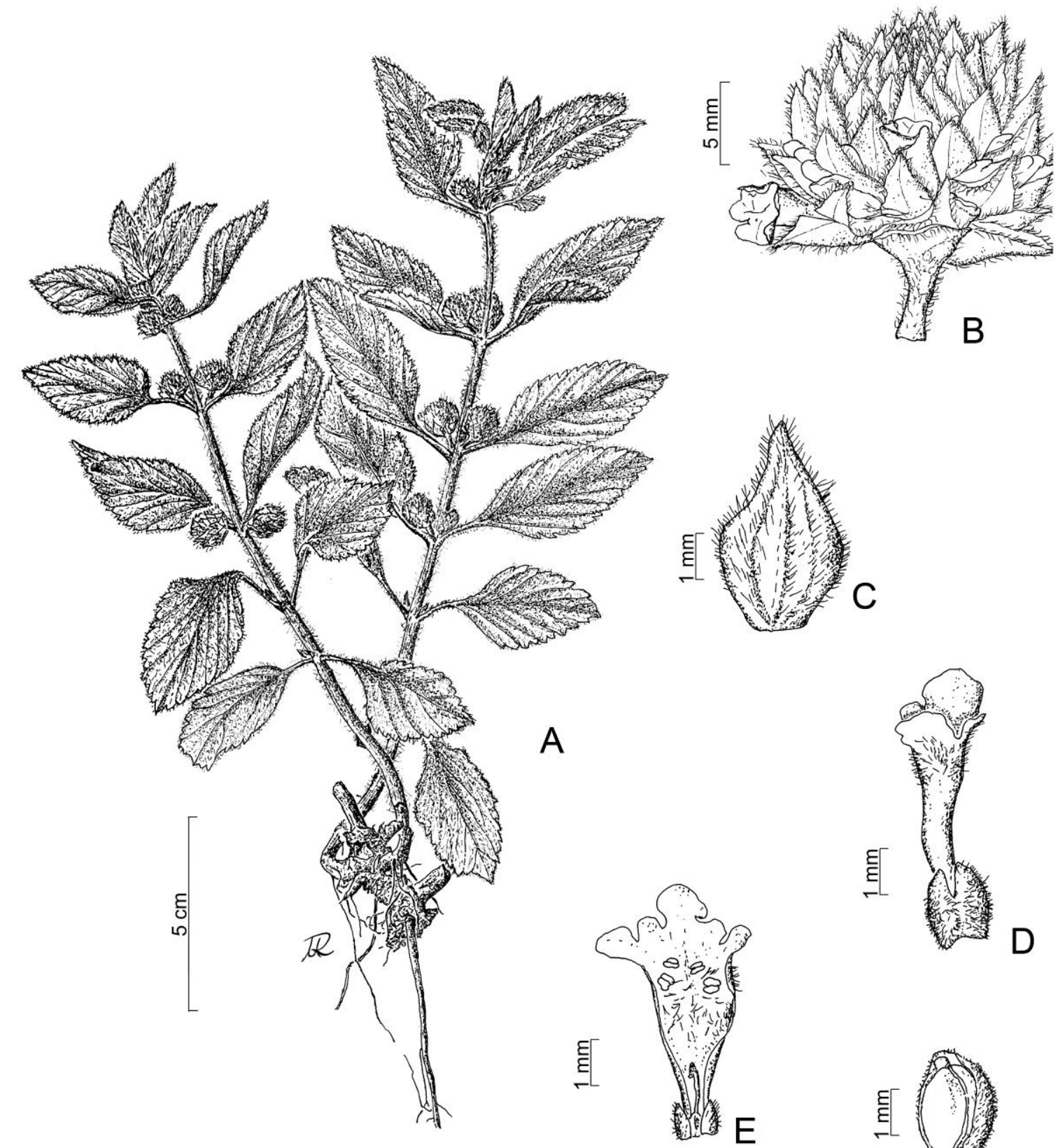

A
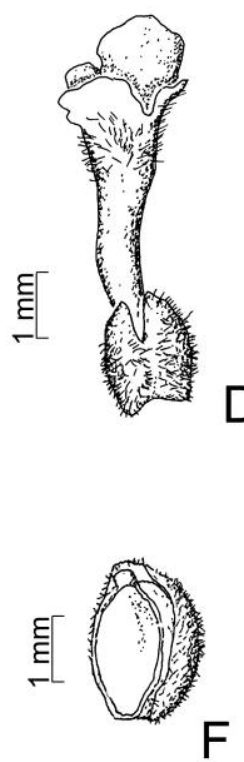

Fig. 1 - Lippia recolletae Morong A-F: A. Hábito; B. Inflorescência; C. Bráctea; D. Flor; E. Corola, seção longitudinal; F. Clusa, face ventral com cálice. (A, C, D, E Cabrera 28188; B, F Balansa 1041) 
Subarbusto monóico, 0,2-1 $\mathrm{m}$ alt., sistema subterrâneo do tipo xilopódio, pouco ramificado, ramos basais, cilíndricos na base, tetragonais, sulcados no ápice, estrigosos, tricomas glandulares longos, patentes, alvos. Folhas decussadas, pecíolos $0,5-1 \mathrm{~cm}$ compr., lâminas 4,5-10 x 2-4,5 cm, ovais, ápice agudo, base cuneada, margem inteira no terço inferior, crenada nos $2 / 3$ superiores, face adaxial hirsuta em ambas as faces, tricomas longos, alvos. Inflorescência em pleiobótrios homotéticos frondosos, hipopódios 3 $15 \mathrm{~mm}$ compr., coflorescências em espigas ca $2 \mathrm{~cm}$ compr., hemisféricas, capituliformes, compactas, axilares, uma por axila, ca. 1,5-2 cm compr, compactas. Flores com brácteas $5,4 \times 4,1 \mathrm{~mm}$, ovais, acuminadas, híspidas, margem ciliada; cálice 1,5-2 $\mathrm{mm}$ compr., globoso, fendido pela metade, corola ca. $6,25 \mathrm{~mm}$ compr., infundibuliforme, amarelada. Fruto ca. $1 \mathrm{~mm}$ diâmetro, esférico, clusas com paredes lisas.

Material examinado: BRASIL. Brasília. Distrito Federal. Parque Nacional de Brasília. 2.XII.2012, C.R Martins 1311 (CESJ). Goiás. Uruaçu, antiga estrada para

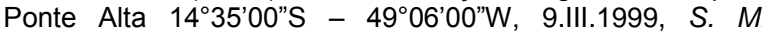
Verboonen et al. 25 (CEN). São Paulo, Itirapina, 13.I.1983, R.A. Camargo s/n (HRCB).

Material examinado adicional: ARGENTINA Corrientes. Mburucuyá: Estancia Santa Teresa, 29.XI.1990, Fortunato et al. 1767 (SI); Colonia San Antonio, ruta 117, a $24 \mathrm{~km} \mathrm{~S}$ de la ruta 12, 23.X.1979, Carnevali 6330 (CTES); General Paz, 1.I.1966, Krapovickas \& Cristóbal 11816 (SI). Misiones. Candelaria, Bonpland, 25.III.1910, Rodríguez 234 (SI). PARAGUAI. Caaguazú, 1905, Hassler 9142 (K). Canindeyú. Reserva Natural Maracayú, de puesto Caarapá hacia Mojón, $23^{\circ} 56^{\prime}$ 'S $55^{\circ} 22^{\prime}$ W, 450 m s.n.m., 6.XII.2003, Múlgura 3561 (SI, MO); Central. Limpio, Paso Correo, 27.V.1987, Zardini 2727 et al. (K, MO); Cerros de Tobaty, 1904, Hassler 6108 (K); Tavarory, 2530' S 57030' W, 17.XI.1990, Zardini 24291 (SI); L'Assoption, IV.1874, Balansa 1041 (G). Cordillera, $9 \mathrm{~km}$ SE of Emboscada on road to Nueva Colombia, $25^{\circ} 09^{\prime}$ S 57 $14^{\prime}$ 'W, 9.VI.1990,
Zardini 21207 (SI). Guairá, 16.XII. 1936, Acher 4667 (MO).Paraguarí: Acahay Massif, 265's 57011' W, 11.XI.1989, Zardini 16121 (SI); Sierra de Amambay, 1907/8, Hassler 9906 (K); Sierra de Maracayú, 1904, Hassler $4958(\mathrm{~K})$.

Lippia recolletae foi descrita por Morong em 1892, baseado em sua coleção de número 62, procedente da região de Recoleta, Paraguai, originando o epíteto específico. Um isótipo desta coleção foi identificado na coleção depositada em K.

A distribuição geográfica de $L$. recolletae era conhecida anteriormente apenas para a Bolívia, Paraguai até o norte da Argentina, e no Brasil havia um registro para o estado do Paraná, de acordo com Múlgura et al. (2003). Este registro, entretanto, é equivocado uma vez que a coleção examinada e citada pelas autoras, Hatschbach 51593, depositada nos herbários MBM, MO e UPCB, é procedente do estado de Mato Grosso do Sul, município de Bela Vista. Dessa forma a citação para o estado do Paraná é errônea. No Brasil $L$. recolletae apresenta distribuição nos cerrados com uma coleção do estado de Goiás, depositado no herbário CEN, e outro registro para o Parque Nacional de Brasília, Distrito Federal, datada de 2012 (Dias \& Salimena 2013) depositado no herbário CESJ. O registro para o estado de São Paulo, datado de 1983, no município de Itirapina, foi encontrado em coleção depositada no herbário HRCB que amplia a área de ocorrência da espécie no território brasileiro. Morong (1892) ressalta o forte odor de menta da espécie, que ocorre em campos secos e arenosos com floração de outubro a fevereiro (Múlgura et al. 2003).

Lippia tegulifera Briq., Annuaire Conserv. Jard. Bot. Genève 7-8: 309. 1904. Tipo. Paraguai. Caaguazú, 7.XI.1874, Balansa 1031 p.p .(lectótipo G!; isótipos K!, NY!, P!, S!). 


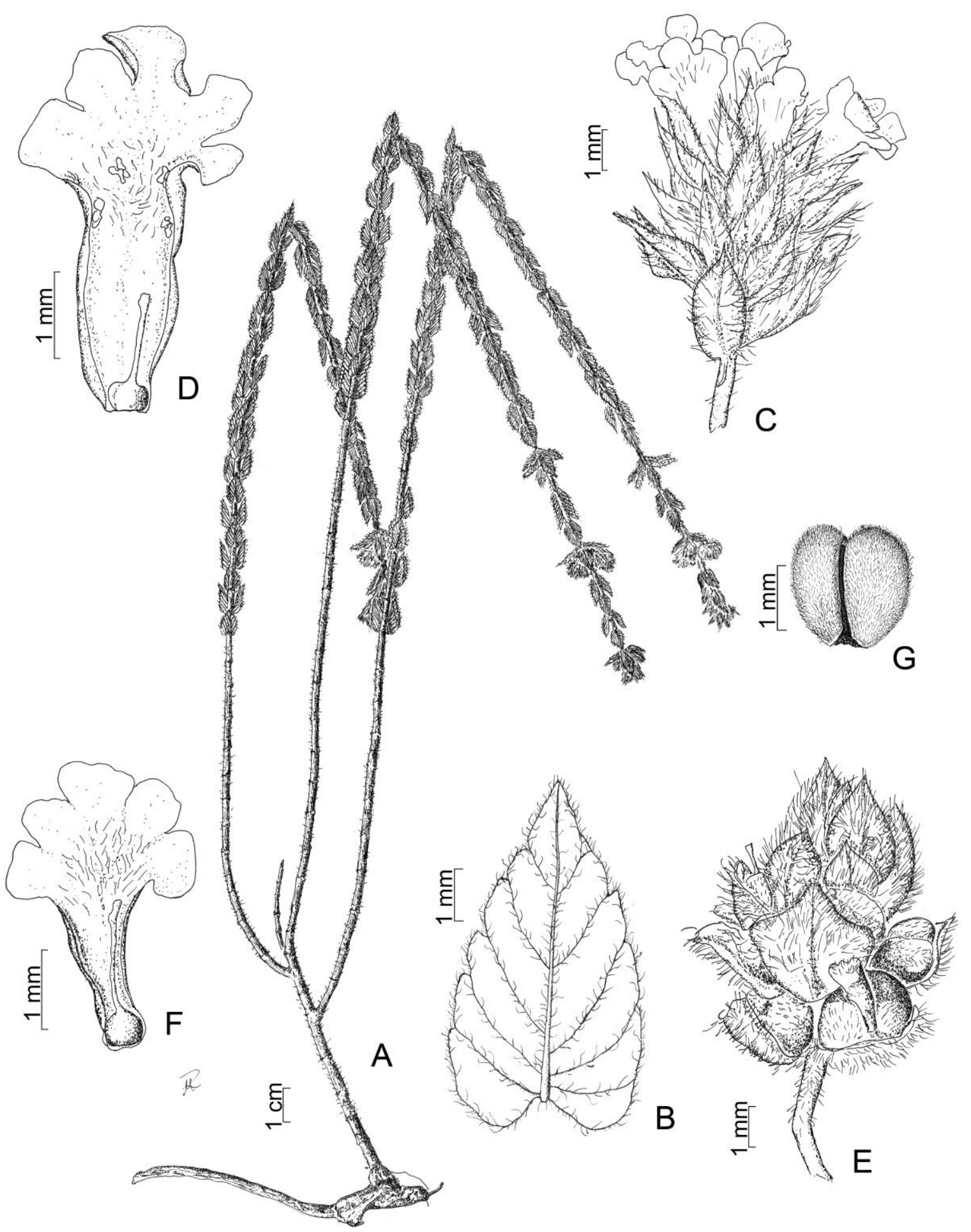

Fig. 2 - Lippia tegulifera Briq. A-G: A. Hábito; B. Folha, face abaxial, C. Inflorescência masculina; D. Flor estaminada, corte longitudinal, E. Inflorescência feminina; F. Flor pistilada, corte longitudinal (A. Krapovickas 28699. B. Hassler 6108. C-D. Pedersen 7671. E. Jorgensen 3780. F. Schinini 15619. G. Balansa 1031). 
Notas sobre o gênero Lippia (Verbenaceae) no Brasil

Subarbusto dióico, 50-60 cm, sistema subterrâneo desenvolvido do tipo xilopódio, ramos subtetragonais, eretos, hirsuto-estrigosos, internós $0,8-1,5 \mathrm{~cm}$. Folhas decussadas, sésseis, apressas, lâminas $0,8-2(5) \times 0,5-0,8(1,5) \mathrm{cm}$, ovais, ápice agudo, base cordada, margem revoluta, crenada; face adaxial estrigosa, tricomas curtos ao longo das nervuras impressas; face abaxial estrigosa, tricomas glandulares pedicelados esparsos. Inflorescências em pleiobótrios homotéticos frondosos, proliferantes; coflorescencias em espigas capituliformes, ca. $1 \mathrm{~cm}$ compr., hipopódios ca. 0,5 cm comp., hirsutoestrigosos. Flores estaminadas: brácteas ca. 0,4 mm, ovais, estrigoso-pubescentes; cálice inconspícuo, ca. 0,5 mm, 2-lobado, externamente pubescente; corola amarela, hipocrateriforme, ca. 3-3,5 $\mathrm{mm}$ compr., externamente pubescente; estames inclusos; pistilódio presente. Flores pistiladas: brácteas ca. $4 \times 3 \mathrm{~mm}$, largo-ovais, côncavas, ápice acuminado, cara abaxial estrigoso-pubescente; sépalas ca. $2 \times 1 \mathrm{~mm}$, côncavas, face abaxial pubescente; corola amarela hipocrateriforme, tubo ca.2 mm compr., externamente pubescente; androceu ausente; estilete ca. 2,3 mm. Fruto obovado a esférico, $2 \times 2 \mathrm{~mm}$ diâm., coberto pelas brácteas e pelo cálice acrescente, clusas hemisféricas, face dorsal lisa, face comissural papilosa.

Material examinado: BRASIL. Paraná: Vila Velha, X.1970, P. Ochioni 4294 (P); Rio Grande do Sul, Santo Augusto, 24.IV.1968, J. Pivetta s.n. (HRCB).

Material examinado adicional: ARGENTINA. Misiones, San Ignacio, entrada al Parque Provincial Teyucuaré, 23.III.1998, Zuloaga 6587 (SI). Corrientes, San Martín, Carlos Pellegrini, $8 \mathrm{~km}$ al N, 30.X.1971, Krapovickas 20128 (SI). PARAGUAI. Caaguazú, 9.XII.1969, Pedersen 9516 (SI). Cordillera, in regione collium, Cerros de Tobaty, II.1902, Hassler 6108, 6108a, 6108b (G). Paraguarí, Cordillera de Altos, 12.XI.1902, Fiebrig 429 (G).

Lippia tegulifera está incluída em Lippia sect. Dioicolippia Tronc. que reúne as espécies dióicas, com xilopódios lenhosos, flores amarelo-alaranjadas, dimorfas, dispostas em espigas capituliformes, subglobosas ou hemisféricas, axilares ou em racemos bracteosos, que são aqui definidos como pleiobótrios homotéticos frondosos (Múlgura de Romero 2000). Destaca-se das demais espécies da seção Dioicolippia que ocorrem no Brasil por apresentar indumento estrigoso, folhas apressas, com base cordada e inflorescências proliferantes.

Lippia tegulifera apresenta distribuição da região central do Paraguai ao nordeste da Argentina (Misiones e Corrientes), sendo esta distribuição ampliada para a região sul do Brasil, onde foi registrada nos estados do Paraná e Rio Grande do Sul
(Múlgura et al. 2003). Ocorre nos campos rochosos e pastagens, florescendo e frutificando de outubro a fevereiro.

\section{Agradecimentos}

As autoras agradecem ao CNPq/ Programa REFLORA (Processo 563560/2010-0), ao INCT pela visita aos herbários da região centro-oeste, aos curadores dos herbários visitados e aos assessores, pela revisão do manuscrito e sugestões.

\section{Referências}

ATKINS, S. 2004. Verbenaceae. In J. W. Kadereit (ed.). The families and genera of flowering plants, vol. 7. Springer. Berlin, p. $449-468$.

DIAS, A. \& SALIMENA, F.R.G. 2013. Nova ocorrência de Lippia recolletae Morong (Verbenaceae J.St.Hil.) para o Distrito Federal. Resumos do $64^{\circ}$. Congresso Nacional de Botânica. Sociedade Botânica do Brasil. Belo Horizonte.

MARX, H., O'LEARY, N., YUAN, Y., LU-IRVING, P., TANK, D., MÚlGURA, M.E. \& OLMSTEAD, R. 2010. A molecular phylogeny and classification of Verbenaceae. Amer. J. Bot. 97(10): 1647-1663.

MÚlguRA, M. E., ROTMAN, A. D. \& ATKINS. S. 2003. Verbenaceae Parte 1. In A.T. Hunziker (ed.). Flora Fanerogamica Argentina. Conicet. Buenos Aires.

MÚLGURA DE ROMERO, M.E. 2000. Las especies de Lippia L. sect. Dioicolippia Tronc. (Verbenaceae). Candollea 55(2): 227-254.

SALIMENA, F., FRANÇA, F. \& SILVA, T.R.S. 2009. Verbenaceae. In A.M. Giulietti, A. Rapini, M.J.G. Andrade, L.P. Queiroz \& J.M.C. Silva (orgs.). Plantas raras do Brasil. Conservação Internacional. Belo Horizonte, p. 399-405.

SALIMENA, F.R.G., KUTSCHENCO, D.C., MONTEIRO, N.P. \& MYSSEN, C. 2013. Verbenaceae. In G. Martinelli \& M.A. Moraes (orgs.). Livro Vermelho da Flora do Brasil. CNCFLORA. Instituto de Pesquisas Jardim Botânico do Rio de Janeiro. Rio de Janeiro, p. 1010-1016.

THIERS, B. [permanentemente atualizado, consulta 2014] Index Herbariorum: A global directory of public herbaria and associated staff. New York Botanical Garden's Virtual Herbarium, http://sweetgum.nybg.org/ih. 